\title{
Sex Differences in Time-Dependent Changes in B-Type Natriuretic Peptide in Hypertrophic Cardiomyopathy
}

\author{
Nobuyuki Enzan, MD; Shouji Matsushima, MD, PhD; Tomomi Ide, MD, PhD; \\ Hidetaka Kaku, MD; Takeshi Tohyama, MD PhD; Kouta Funakoshi, MD; \\ Taiki Higo, MD; Hiroyuki Tsutsui, MD, PhD
}

\begin{abstract}
Background: Female sex is reported to be associated with poor prognosis in hypertrophic cardiomyopathy (HCM). The plasma B-type natriuretic peptide (BNP) concentration is a prognostic predictor in HCM. However, the effect of sex on BNP concentrations remains unclear among HCM patients.

Methods and Results: Patient records in the Clinical Personal Records of HCM national database of the Japanese Ministry of Health, Labour and Welfare from 2009 to 2014 were analyzed. Of 3,570 HCM patients, 611 in whom BNP concentrations were assessed at both baseline and the 2-year follow-up were included in this analysis. The mean age was 60.4 years and 254 (41.6\%) patients were female. Median (interquartile range) BNP concentrations were higher in females than males at both baseline (320.3 [159.0-583.1] vs. 182.8 [86.1-363.9] pg/mL; P<0.001) and the 2-year follow-up (299.2 [147.0-535.3] vs. 161.0 [76.2-310.0] pg/mL; $\mathrm{P}<0.001)$. Female sex was associated with higher natural log-transformed BNP at the 2-year follow-up regardless of clinical characteristics, including echocardiographic findings and BNP concentrations at baseline (coefficient $0.31 ; 95 \%$ confidence interval $0.13-0.48 ; P<0.001)$. Cubic spline analysis showed that, among patients with high BNP concentrations at baseline, females had higher BNP concentrations at the 2-year follow-up than males.
\end{abstract}

Conclusions: In HCM, female sex was associated with higher BNP concentrations than male sex, independent of clinical characteristics, including BNP concentrations at baseline.

Key Words: B-type natriuretic peptide; Hypertrophic cardiomyopathy; Sex difference

$\mathbf{H}$ ypertrophic cardiomyopathy $(\mathrm{HCM})$ is an inherited cardiac disorder, with an estimated prevalence of $1: 500 .^{1}$ Gene mutations are detectable in $75 \%$ of $\mathrm{HCM}$ patients, the most common of which are in the cardiac myosin-binding protein $\mathrm{C}(M Y B P C 3)$ and $\beta$-myosin heavy chain (MYH7) genes., ${ }^{2,3}$ Although the mode of inheritance is autosomal dominant, male patients had a $3: 2$ predominance, ${ }^{4-7}$ suggesting the existence of sex differences in this disease. Indeed, there are several reports regarding sex differences in clinical features, cardiac morphology, and prognosis in HCM.,6,8-13 In general, female HCM patients are known to be under-represented, older, and more symptomatic, as well as having a higher risk of heart failure (HF) with an outflow obstructive phenotype, than males. ${ }^{4}$ Importantly, female sex is reported to be associated with poor prognosis., ${ }^{4,6,10,14}$ Recently, therapeu- tic options for HCM have been developed, including implantable defibrillator, myectomy, and alcohol septal ablation to avert lethal ventricular arrhythmia and HF death and morbidity. In order for better stratification in $\mathrm{HCM}$, it is clinically relevant to clarify sex differences not only for mortality, but also for surrogate outcomes.

B-type natriuretic peptide (BNP) is useful in predicting prognosis in several cardiovascular diseases. ${ }^{15-18}$ In HCM, elevated BNP concentrations are associated with sudden death ${ }^{19}$ and progression to end-stage disease. ${ }^{20}$ In addition, $\mathrm{BNP}$ is reported to be a prognostic predictor, independent of left ventricular (LV) mass and fibrosis. ${ }^{21}$ Furthermore, persistent elevation of BNP concentrations has been shown to be predictive of long-term major adverse cardiovascular events. ${ }^{22}$ However, sex differences in BNP concentrations, particularly time-dependent changes in BNP, among HCM

Received August 11, 2021; accepted August 11, 2021; J-STAGE Advance Publication released online September 30, 2021 Time for primary review: 1 day

Department of Cardiovascular Medicine, Faculty of Medical Sciences, Kyushu University, Fukuoka (N.E., S.M., T.I., H.T.); Department of Cardiology, Japan Community Healthcare Organization Kyushu Hospital, Fukuoka (H.K.); Center for Clinical and Translational Research, Kyushu University Hospital, Fukuoka (T.T., K.F.); and Department of Cardiovascular Medicine, National Hospital Organization, Kyushu Medical Center, Fukuoka (T.H.), Japan

T.I. is a member of Circulation Reports' Editorial Team.

Mailing address: Shouji Matsushima, MD, PhD, Department of Cardiovascular Medicine, Kyushu University Hospital, 3-1-1 Maidashi, Higashi-ku, Fukuoka 812-8582, Japan. E-mail: matsushima.shoji.056@m.kyushu-u.ac.jp

All rights are reserved to the Japanese Circulation Society. For permissions, please e-mail: cr@j-circ.or.jp

ISSN-2434-0790 


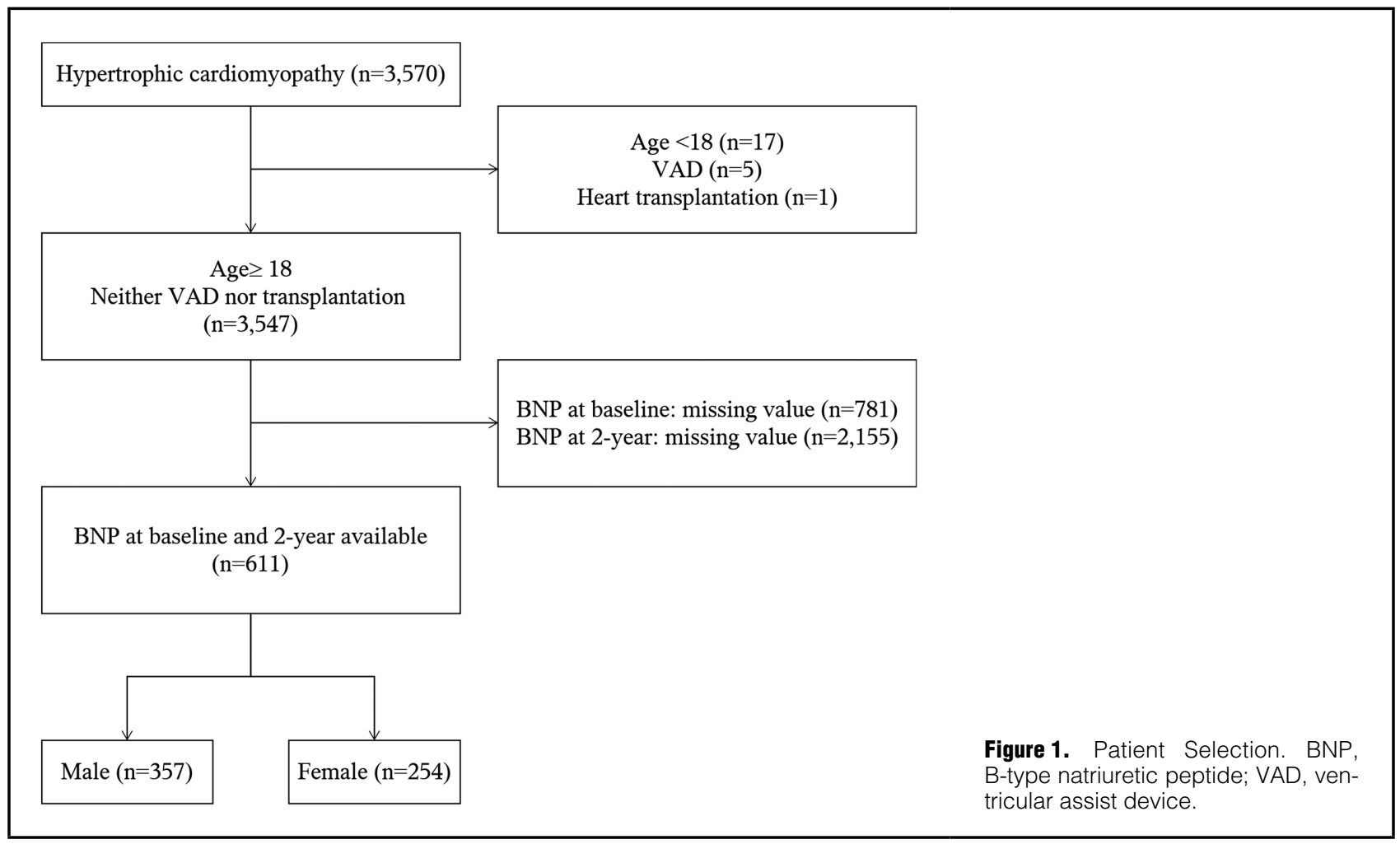

patients remain unclear.

The Clinical Personal Record is a nationwide administrative database of public expenditure for refractory disease of the Japanese Ministry of Health, Labour and Welfare in which intractable diseases throughout Japan, including cardiomyopathy, are registered and certified. This database is useful for investigating the clinical features of and routine practice regarding HCM patients in Japan. ${ }^{23}$ The aim of this study was to clarify sex differences in BNP levels among HCM patients by using the nationwide Clinical Personal Record registry.

\section{Methods}

\section{Clinical Personal Record}

The Clinical Personal Record of HCM, a nationwide administrative database of public expenditure for refractory disease, prospectively and annually collects the following: (1) demographic data (age, sex, HF duration, and New York Heart Association [NYHA] functional class); (2) vital signs; (3) comorbidities; (4) electrocardiographic data; (5) echocardiographic data; (6) laboratory data; and (7) medication use. This database does not collect information about clinical outcomes, such as cardiovascular death and all-cause death. HCM was diagnosed as asymmetric or diffuse LV hypertrophy with reduced diastolic function in the absence of any specific cardiac or systemic diseases, such as hypertensive heart disease, valvular heart disease, congenital heart disease, coronary artery disease, alcoholic cardiomyopathy, cardiomyopathy caused by toxins/medications, amyloidosis, sarcoidosis, connective tissue disease, and dystrophy, or metabolic diseases such as Pompe disease or Fabry disease. All database entries were registered after being reviewed by certified cardiologists. In this study, we analyzed this nationwide database for the period 2009-2014.

\section{Study Population}

Patients aged $>18$ years were identified in the Clinical Personal Record of HCM. Patients who received an LV assist device (LVAD) or underwent heart transplantation during the follow-up period or those whose BNP concentrations were not assessed at baseline or the 2-year follow-up were excluded from the study.

\section{BNP Measurement}

BNP was measured at each participating hospital. Plasma BNP concentrations at baseline and the 2-year follow-up were analyzed according to sex.

\section{Statistical Analysis}

Patient characteristics, including age, sex, NYHA functional class, HF duration, vital signs, electrocardiographic findings, echocardiographic findings, comorbidities, laboratory data, and medications, were compared using Pearson's $\chi^{2}$ test for categorical variables or Student's t-test or the Wilcoxon rank-sum test for continuous variables and are presented as the mean $\pm \mathrm{SD}$ or as the median with interquartile range (IQR).

Changes in BNP concentrations from baseline to the 2-year follow-up were examined by paired t-test after log transformation of BNP data. The coefficient for natural log-transformed BNP at the 2-year follow-up was estimated using analysis of covariance (ANCOVA) including female sex, natural log-transformed BNP at baseline, and other covariates, as listed below, and is reported with $95 \%$ confidence intervals $(\mathrm{CI})$ and $\mathrm{P}$ values. We examined the outcomes using several ANCOVA models, including 
covariates as follows:

Model 1: demographics and vital signs (age, HCM duration, NYHA functional class, systolic blood pressure, and heart rate)

Model 2: Model 1+comorbidities (hypertension and stroke)

Model 3: Model 2+electrocardiographic findings and devices (atrial fibrillation, pacemaker, implantable cardioverter defibrillator, and cardiac resynchronization therapy) Model 4: Model 3+echocardiographic findings (LV ejection fraction [LVEF], interventricular septal wall [IVS] thickness, LV posterior wall [LVPW] thickness, left atrial diameter, mitral regurgitation, and LV obstruction) Model 5: Model 4+ laboratory data (albumin and estimated glomerular filtration rate)

Model 6: Model 5+medication ( $\beta$-blockers, angiotensin-converting enzyme inhibitors [ACEI]/angiotensin II receptor blockers [ARB], and mineralocorticoid receptor antagonists).

\begin{tabular}{|c|c|c|c|}
\hline & $\begin{array}{c}\text { Males } \\
(n=357)\end{array}$ & $\begin{array}{l}\text { Females } \\
(n=254)\end{array}$ & $P$ value \\
\hline \multicolumn{4}{|l|}{ Demographics } \\
\hline Age (years) & $60.0 \pm 13.5$ & $60.9 \pm 15.5$ & 0.47 \\
\hline Disease duration (years) & $8[3-16]$ & $8[3-15]$ & 0.88 \\
\hline NYHA functional class III-IV & $33(9.8)$ & $27(11.6)$ & 0.48 \\
\hline \multicolumn{4}{|l|}{ Family history } \\
\hline Hypertrophic cardiomyopathy & $87(24.4)$ & $82(32.3)$ & 0.031 \\
\hline Sudden cardiac death & $28(7.8)$ & $25(9.8)$ & 0.39 \\
\hline \multicolumn{4}{|l|}{ Vital signs } \\
\hline Systolic blood pressure $(\mathrm{mmHg})$ & $119.9 \pm 17.6$ & $119.9 \pm 19.1$ & 1.00 \\
\hline Diastolic blood pressure $(\mathrm{mmHg})$ & $70.1 \pm 12.6$ & $69.0 \pm 13.5$ & 0.34 \\
\hline Heart rate (beats/min) & $68.0 \pm 15.7$ & $66.3 \pm 12.9$ & 0.16 \\
\hline \multicolumn{4}{|l|}{ Comorbidities } \\
\hline Hypertension & $66(29.1)$ & $45(27.1)$ & 0.67 \\
\hline CKD stage $3-5$ & $124(35.6)$ & $119(47.4)$ & 0.004 \\
\hline Stroke & $9(2.5)$ & $3(1.2)$ & 0.24 \\
\hline \multicolumn{4}{|l|}{ Electrocardiographic findings } \\
\hline Atrial fibrillation & $120(33.6)$ & $51(20.1)$ & $<0.001$ \\
\hline Ventricular fibrillation or tachycardia & $122(34.2)$ & $50(19.7)$ & $<0.001$ \\
\hline Pacemaker & $15(4.2)$ & $22(8.7)$ & 0.023 \\
\hline Implantable cardioverter defibrillator & $17(4.8)$ & $10(3.9)$ & 0.62 \\
\hline Cardiac resynchronization therapy & $2(0.6)$ & $1(0.4)$ & 0.77 \\
\hline Right bundle branch block & $25(11.0)$ & $16(9.6)$ & 0.66 \\
\hline Left bundle branch block & $9(4.0)$ & $4(2.4)$ & 0.39 \\
\hline \multicolumn{4}{|l|}{ Echocardiographic findings } \\
\hline LVEF (\%) & $61.4 \pm 16.0$ & $64.7 \pm 14.5$ & 0.012 \\
\hline LVDd (mm) & $48.0 \pm 8.0$ & $43.4 \pm 7.8$ & $<0.001$ \\
\hline LVDs (mm) & $31.2 \pm 9.0$ & $27.3 \pm 8.9$ & $<0.001$ \\
\hline IVS (mm) & $16.4 \pm 5.5$ & $15.6 \pm 4.8$ & 0.062 \\
\hline LVPW (mm) & $11.9 \pm 3.8$ & $11.2 \pm 3.0$ & 0.011 \\
\hline Left atrial diameter (mm) & $45.8 \pm 10.1$ & $41.8 \pm 8.8$ & $<0.001$ \\
\hline E wave $(\mathrm{cm} / \mathrm{s})$ & $67.5 \pm 24.1$ & $74.8 \pm 30.0$ & 0.006 \\
\hline A wave $(\mathrm{cm} / \mathrm{s})$ & $64.5 \pm 33.4$ & $74.0 \pm 38.3$ & 0.010 \\
\hline $\mathrm{e}^{\prime}(\mathrm{cm} / \mathrm{s})$ & $5.5 \pm 2.8$ & $5.5 \pm 3.0$ & 0.93 \\
\hline$E / A$ & $1.2 \pm 0.7$ & $1.2 \pm 0.6$ & 0.55 \\
\hline$E / e^{\prime}$ & $14.3 \pm 7.0$ & $16.9 \pm 7.6$ & 0.012 \\
\hline Deceleration time (ms) & $216.4 \pm 73.7$ & $242.4 \pm 87.1$ & 0.002 \\
\hline TR velocity $(\mathrm{m} / \mathrm{s})$ & $2.7 \pm 0.5$ & $2.7 \pm 0.5$ & 0.77 \\
\hline MR III-IV & $22(7.9)$ & $23(11.2)$ & 0.21 \\
\hline Left ventricular obstruction & $96(26.9)$ & $112(44.1)$ & $<0.001$ \\
\hline LVOT obstruction & $73(20.4)$ & 87 (34.3) & $<0.001$ \\
\hline LVOT gradient $>50 \mathrm{mmHg}$ & $55(15.4)$ & $67(26.4)$ & 0.001 \\
\hline LV mid obstruction & $26(7.3)$ & $30(11.8)$ & 0.056 \\
\hline Pericardial effusion & $15(4.2)$ & $19(7.5)$ & 0.081 \\
\hline
\end{tabular}

(Table 1 continued the next page.) 


\begin{tabular}{|c|c|c|c|}
\hline & $\begin{array}{c}\text { Males } \\
(n=357)\end{array}$ & $\begin{array}{c}\text { Females } \\
(n=254)\end{array}$ & $P$ value \\
\hline \multicolumn{4}{|l|}{ Laboratory data } \\
\hline Hemoglobin (g/dL) & $14.5 \pm 1.6$ & $12.9 \pm 1.3$ & $<0.001$ \\
\hline Albumin (g/dL) & $4.2 \pm 0.4$ & $4.1 \pm 0.5$ & 0.079 \\
\hline BUN (mg/dL) & $18.4 \pm 13.3$ & $18.0 \pm 12.6$ & 0.65 \\
\hline Creatinine (mg/dL) & $0.91[0.82-1.09]$ & $0.74[0.64-0.89]$ & $<0.001$ \\
\hline eGFR $\left(\mathrm{mL} / \mathrm{min} / 1.73 \mathrm{~m}^{2}\right)$ & $65.5 \pm 18.0$ & $63.1 \pm 20.4$ & 0.15 \\
\hline Uric acid (mg/dL) & $6.5 \pm 1.4$ & $5.5 \pm 1.5$ & $<0.001$ \\
\hline Sodium (mEq/L) & $140.6 \pm 2.7$ & $141.0 \pm 2.6$ & 0.077 \\
\hline Potassium (mEq/L) & $4.3 \pm 0.5$ & $4.3 \pm 0.5$ & 0.68 \\
\hline $\mathrm{BNP}(\mathrm{pg} / \mathrm{mL})$ & 182.8 [86.1-363.9] & $320.3[159.0-583.1]$ & $<0.001$ \\
\hline $\ln [\mathrm{BNP}]$ & $5.2 \pm 1.1$ & $5.7 \pm 1.1$ & $<0.001$ \\
\hline \multicolumn{4}{|l|}{ Medication } \\
\hline$\beta$-blockers & $218(61.1)$ & $138(55.0)$ & 0.13 \\
\hline ACEI or ARB & $221(61.9)$ & $123(48.4)$ & 0.001 \\
\hline MRA & $74(20.7)$ & $61(24.0)$ & 0.33 \\
\hline Dihydropyridine CCB & $54(15.1)$ & $25(9.8)$ & 0.055 \\
\hline Verapamil & $23(6.4)$ & $21(8.3)$ & 0.39 \\
\hline Diltiazem & $19(5.3)$ & $14(5.5)$ & 0.92 \\
\hline Loop diuretics & $100(28.0)$ & $72(28.3)$ & 0.93 \\
\hline Thiazides & $18(5.0)$ & $10(3.9)$ & 0.52 \\
\hline Digitalis & $11(3.1)$ & $10(3.9)$ & 0.57 \\
\hline Amiodarone & $57(16.0)$ & $23(9.1)$ & 0.013 \\
\hline Disopyramide & $12(3.4)$ & $22(8.7)$ & 0.005 \\
\hline Cibenzoline & $43(12.1)$ & $65(25.7)$ & $<0.001$ \\
\hline Oral inotropes & $5(2.5)$ & $2(1.4)$ & 0.48 \\
\hline
\end{tabular}

Unless specified otherwise, data are shown as $\mathrm{n}(\%)$, the mean $\pm \mathrm{SD}$, or median [interquartile range]. ACEl, angiotensinconverting enzyme inhibitors; ARB, angiotensin II receptor blockers; BNP, B-type natriuretic peptide; BUN, blood urea nitrogen; CCB, calcium channel blockers; CKD, chronic kidney disease; eGFR, estimated glomerular filtration rate; IVS, interventricular septal thickness; In, natural log; LV, left ventricular; LVDd, left ventricular diastolic diameter; LVEF, left ventricular ejection fraction; LVDs, left ventricular systolic diameter; LVOT, left ventricular outflow tract; LVPW, left ventricular posterior wall thickness; MR, mitral regurgitation; MRA, mineralocorticoid receptor antagonists; NYHA, New York Heart Association; TR, tricuspid regurgitation.

We examined outcomes in patients with or without LV obstruction separately using Model 1 . We also performed a multivariate analysis, including covariates that were significant on univariate analysis for natural log-transformed BNP at the 2-year follow-up. Outcomes were also analyzed using a combination of multiple imputation and multivariate analysis to assess the effects of missing data. For all missing data at baseline, multiple imputation was performed (10 imputed datasets) by predictive mean matching for continuous variables and using a logistic regression model for binary variables. The multivariate analysis included covariates used in multiple imputations. Coefficients for natural log-transformed BNP concentrations at the 2-year follow-up from 10 iterations were combined using Rubin's rule. To model the effects of sex on changes in BNP, a cubic spline analysis adjusted for age and LVEF was performed. To assess the effects of selection bias, we compared baseline characteristics of eligible patients with those who were excluded because their BNP was not assessed at the 2-year follow-up.

All tests were 2-tailed and $\mathrm{P}<0.05$ was considered statistically significant. All analyses were performed using SAS version 9.4 (SAS Institute, Cary, NC, USA).

\section{Ethics Statement}

The study protocol complied with the Declaration of
Helsinki. The original study protocol was approved by the Institutional Review Board at Kyushu University. An "opt-out" approach was applied to consent because this study analyzed a nationwide administrative database.

\section{Results}

\section{Baseline Characteristics}

From 2009 to 2014, 3,570 consecutive patients with HCM were screened and 3,547 patients aged $>18$ years who did not receive an LVAD and did not undergo heart transplantation during the follow-up period were identified (Figure 1). Of these patients, 611 who had BNP assessed at both baseline and the 2-year follow-up were included in the present analysis. There was a predominance of males $(n=357 ; 58.4 \%)$ compared with females $(n=254 ; 41.6 \%)$. Comparing female and male HCM patients, there were no significant differences in age $(60.9 \pm 15.5$ vs. $60.0 \pm 13.5$ years, respectively; $\mathrm{P}=0.47)$ or disease duration $(8[3-15]$ vs. 8 [3-16] years, respectively; $\mathrm{P}=0.88$; Table 1). We also compared eligible patients with those patients who did not have BNP assessed at the 2-year follow-up. Although the latter group was older ( $62.2 \pm 15.0$ vs. $60.4 \pm 14.4$ years; standardized mean difference [SMD] 0.123; $\mathrm{P}=0.010$ ), the echocardiographic findings and BNP concentrations at baseline (245.9 [104.6-530.0] vs. 233.1 [114.6-465.0] pg/mL; SMD 


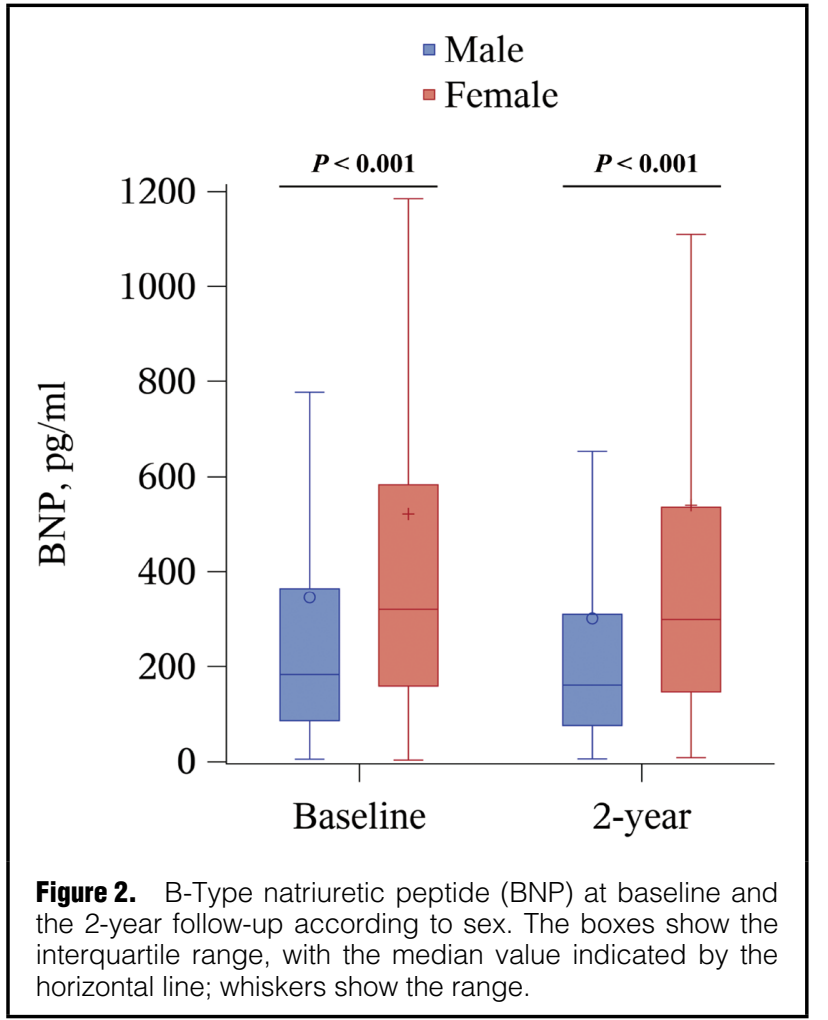

0.053; $\mathrm{P}=0.40)$ were similar between the 2 groups (Supplementary Table 1).

\section{Echocardiography}

Compared with males, females with HCM had a greater LVEF (64.7 $\pm 14.5 \%$ vs. $61.4 \pm 16.0 \%$; $=0.012)$, smaller LV diastolic diameter $(43.4 \pm 7.8$ vs. $48.0 \pm 8.0 \mathrm{~mm} ; \mathrm{P}<0.001)$, smaller LV systolic diameter $(27.3 \pm 8.9$ vs. $31.2 \pm 9.0 \mathrm{~mm}$; $\mathrm{P}<0.001)$, smaller left atrial transverse dimensions $(41.8 \pm 8.8$ vs. $45.8 \pm 10.1 \mathrm{~mm} ; \mathrm{P}<0.001)$, slightly lower IVS thickness (15.6 \pm 4.8 vs. $16.4 \pm 5.5 \mathrm{~mm} ; \mathrm{P}=0.061)$, lower LVPW thickness $(11.2 \pm 3.0$ vs. $11.9 \pm 3.8 \mathrm{~mm} ; \mathrm{P}=0.011)$, a higher $\mathrm{E} / \mathrm{e}$ ' ratio ( $16.9 \pm 7.6$ vs. $14.3 \pm 7.0 ; \mathrm{P}=0.012)$, and longer deceleration time $(242.4 \pm 87.1$ vs. $216.4 \pm 73.7 \mathrm{~ms} ; \mathrm{P}=0.001$; Table 1$)$.
Females had a higher prevalence of LV outflow obstruction $(34.3 \%$ vs. $20.5 \%$; $\mathrm{P}<0.001)$ and any $\mathrm{LV}$ obstruction, including outflow obstruction and mid-ventricular obstruction (44.1\% vs. $26.9 \%$; $\mathrm{P}<0.001$; Table 1).

\section{Plasma BNP Concentrations}

Median (IQR) BNP concentrations at both baseline (320.3 [159.0-583.1] vs. 182.8 [86.1-363.9] $\mathrm{pg} / \mathrm{mL}$; $\mathrm{P}<0.001)$ and the 2-year follow-up (299.2 [147.0-535.3] vs. 161.0 [76.2-310.0] pg/mL; $\mathrm{P}<0.001)$ were higher in females than males (Figure 2). Natural log-transformed BNP at the 2-year follow-up was higher in female patients in multivariate models 1 (Model 1: coefficient $0.31,95 \%$ CI $0.13-$ $0.48 ; \mathrm{P}<0.001$; Table 2). The same results were confirmed in multivariate Models 2-6 (Table 2). Furthermore, multiple imputation analysis also demonstrated that BNP at the 2-year follow-up was higher in female patients (coefficient 0.63, 95\% CI 0.44-0.82; P<0.001; Table 2). Natural log-transformed BNP at the 2-year follow-up was higher in female patients with or without LV obstruction (coefficients 0.33 [95\% CI 0.02-0.63; $\mathrm{P}=0.034]$ and 0.29 [95\% CI 0.08-0.50; $\mathrm{P}=0.007]$, respectively; Supplementary Table 2). Multivariate analysis (including covariates significant on univariate analysis) also showed that natural log-transformed BNP at the 2-year follow-up was higher in female patients (coefficient $0.36,95 \% \mathrm{CI}$ 0.05-0.67; $\mathrm{P}=0.024$; Table 3). After adjusting for age and LVEF, cubic spline analysis also demonstrated that females had higher BNP concentrations at the 2-year follow-up than males (Figure 3).

\section{Outcomes}

De novo HF hospitalization was numerically more frequent in females, but the difference did not reach statistical significance $(15.3 \%$ vs. $9.3 \%$; odds ratio $1.75,95 \%$ CI $0.98-$ 3.13; $\mathrm{P}=0.059$; Table 4). There was no significant difference in new-onset atrial fibrillation, lethal ventricular arrhythmia, and stroke between males and females (Table 4).

\section{Discussion}

The major finding of this study was that BNP concentrations at the 2-year follow-up were higher in females than males after adjusting for baseline covariates, including

\begin{tabular}{|c|c|c|}
\hline Analysis & $\begin{array}{l}\text { Coefficient for female sex } \\
\qquad(95 \% \mathrm{Cl})\end{array}$ & $P$ value \\
\hline \multicolumn{3}{|l|}{ Complete case analysis } \\
\hline Model 1 (demographics, vital signs) & $0.31(0.13-0.48)$ & $<0.001$ \\
\hline Model 2 (Model $1+$ comorbidities) & $0.41(0.18-0.64)$ & $<0.001$ \\
\hline Model 3 (Model 2+ECG findings) & $0.42(0.19-0.65)$ & $<0.001$ \\
\hline Model 4 (Model 3+UCG findings) & $0.47(0.16-0.78)$ & 0.003 \\
\hline Model 5 (Model $4+$ laboratory data) & $0.38(0.04-0.72)$ & 0.030 \\
\hline Model 6 (Model $5+$ medication) & $0.36(0.01-0.70)$ & 0.043 \\
\hline Multiple imputation analysis & $0.63(0.44-0.82)$ & $<0.001$ \\
\hline
\end{tabular}

Model 1: Analysis of covariance including female sex, natural log-transformed BNP at baseline, age, hypertrophic cardiomyopathy duration, NYHA functional class, systolic blood pressure, and heart rate. Model 2: Model 1+hypertension and stroke. Model 3: Model 2+atrial fibrillation, pacemaker, implantable cardioverter defibrillator, and cardiac resynchronization therapy. Model 4: Model 3+LVEF, IVS, LVPW, left atrial diameter, MR, and left ventricular obstruction. Model 5: Model $4+$ albumin and estimated glomerular filtration rate. Model 6: Model $5+\beta$-blockers, ACEI/ ARB, and MRA. CI, confidence interval; ECG, electrocardiogram; UCG, ultrasound cardiogram. Other abbreviations as in Table 1. 


\begin{tabular}{|c|c|c|c|c|}
\hline \multirow{2}{*}{ Variables } & \multicolumn{2}{|c|}{ Univariate analysis } & \multicolumn{2}{|c|}{ Multivariate analysis } \\
\hline & Coefficient $(95 \% \mathrm{Cl})$ & $P$ value & Coefficient $(95 \% \mathrm{Cl})$ & $P$ value \\
\hline Female sex & $0.65(0.48,0.83)$ & $<0.001$ & $0.36(0.05,0.67)$ & 0.024 \\
\hline Age & $0.07(0.00,0.13)$ & 0.036 & $0.01(0.00,0.03)$ & 0.008 \\
\hline Disease duration & $0.02(0.01,0.03)$ & $<0.001$ & $0.02(0.00,0.03)$ & 0.038 \\
\hline NYHA functional class & $0.26(-0.05,0.57)$ & 0.10 & & \\
\hline Systolic blood pressure & $-0.14(-0.19,-0.09)$ & $<0.001$ & $-0.01(-0.02,0.00)$ & 0.014 \\
\hline Heart rate & $-0.08(-0.14,-0.01)$ & 0.026 & $-0.01(-0.02,0.00)$ & 0.01 \\
\hline Hypertension & $-0.31(-0.57,-0.05)$ & 0.018 & $0.06(-0.25,0.36)$ & 0.71 \\
\hline Stroke & $-0.19(-0.85,0.48)$ & 0.58 & & \\
\hline Atrial fibrillation & $0.25(0.04,0.45)$ & 0.018 & $0.08(-0.24,0.41)$ & 0.62 \\
\hline Ventricular arrhythmia & $0.01(-0.20,0.21)$ & 0.93 & & \\
\hline Pacemaker & $0.24(-0.14,0.63)$ & 0.22 & & \\
\hline Implantable cardioverter defibrillator & $0.22(-0.23,0.67)$ & 0.33 & & \\
\hline Cardiac resynchronization therapy & $1.16(-0.15,2.48)$ & 0.083 & & \\
\hline Right bundle branch block & $0.10(-0.29,0.48)$ & 0.61 & & \\
\hline Left bundle branch block & $0.26(-0.40,0.92)$ & 0.44 & & \\
\hline LVEF & $-0.05(-0.11,0.01)$ & 0.13 & & \\
\hline LVDd & $-0.23(-0.34,-0.12)$ & $<0.001$ & $-0.02(-0.04,0.00)$ & 0.024 \\
\hline LVDs & $-0.05(-0.16,0.05)$ & 0.32 & & \\
\hline IVS & $0.02(0.00,0.04)$ & 0.016 & $0.01(-0.02,0.04)$ & 0.45 \\
\hline LVPW & $0.00(-0.03,0.03)$ & 0.91 & & \\
\hline Left atrial diameter & $0.15(0.05,0.25)$ & 0.004 & $0.01(0.00,0.02)$ & 0.12 \\
\hline MR & $0.46(0.10,0.82)$ & 0.013 & $0.19(-0.26,0.63)$ & 0.41 \\
\hline LV obstruction & $0.26(0.07,0.45)$ & 0.009 & $0.01(-0.28,0.31)$ & 0.93 \\
\hline Systolic anterior movement & $0.20(-0.82,1.22)$ & 0.70 & & \\
\hline Pericardial effusion & $0.74(0.34,1.13)$ & $<0.001$ & $0.58(0.15,1.00)$ & 0.008 \\
\hline Apical hypertrophy & $0.00(-0.94,0.93)$ & $>0.99$ & & \\
\hline Hemoglobin & $-0.13(-0.19,-0.08)$ & $<0.001$ & $0.02(-0.07,0.11)$ & 0.68 \\
\hline Albumin & $-0.10(-0.36,0.16)$ & 0.44 & & \\
\hline eGFR & $-0.09(-0.14,-0.04)$ & $<0.001$ & $0.00(0.00,0.01)$ & 0.37 \\
\hline Uric acid & $0.00(-0.06,0.07)$ & 0.89 & & \\
\hline Sodium & $-0.24(-0.60,0.12)$ & 0.19 & & \\
\hline Potassium & $0.11(-0.10,0.31)$ & 0.31 & & \\
\hline $\ln [\mathrm{BNP}]$ & $0.67(0.61,0.73)$ & $<0.001$ & $0.59(0.47,0.71)$ & $<0.001$ \\
\hline$\beta$-blockers & $0.02(-0.17,0.21)$ & 0.84 & & \\
\hline ACEI or ARB & $-0.15(-0.34,0.03)$ & 0.11 & & \\
\hline MRA & $0.37(0.15,0.59)$ & 0.001 & $0.21(-0.12,0.54)$ & 0.20 \\
\hline Loop diuretics & $0.33(0.13,0.53)$ & 0.001 & $0.11(-0.22,0.44)$ & 0.52 \\
\hline Thiazide & $-0.17(-0.61,0.27)$ & 0.44 & & \\
\hline Digitalis & $0.52(0.01,1.02)$ & 0.045 & $-1.28(-2.22,-0.33)$ & 0.008 \\
\hline Amiodarone & $0.02(-0.26,0.29)$ & 0.90 & & \\
\hline Oral inotrope & $0.30(-0.60,1.19)$ & 0.52 & & \\
\hline
\end{tabular}

Abbreviations as in Tables 1,2.

LVEF, wall thickness, LV outflow obstruction, and baseline BNP concentration. This is the first report assessing the effect of sex on time-dependent changes in BNP among patients with HCM.

Several sex differences in clinical features of HCM have been reported. A Mayo Clinic study analyzing the largest database of HCM showed that females with HCM had worse outcomes than males. ${ }^{6}$ The Tufts Institute study showed that females developed advanced HF symptoms more frequently than males. ${ }^{13}$ Other studies showed that female sex was associated with progression to severe HF and death.,9,10 The results of the present study, namely that females have higher BNP concentrations not only at baseline but also at the 2-year follow-up, provide evidence supporting the sex difference in HF progression in patients with HCM. Indeed, female sex was more likely associated with a higher rate of de novo HF hospitalization $(\mathrm{P}=0.059$; Table 4). However, it is still unclear whether higher BNP concentrations in female HCM patients affect prognosis because we were not able to collect information regarding mortality, cardiovascular events, or rehospitalization due to HF. Further investigations are needed to elucidate the relationship between sex differences in BNP and prognosis in HCM patients. 


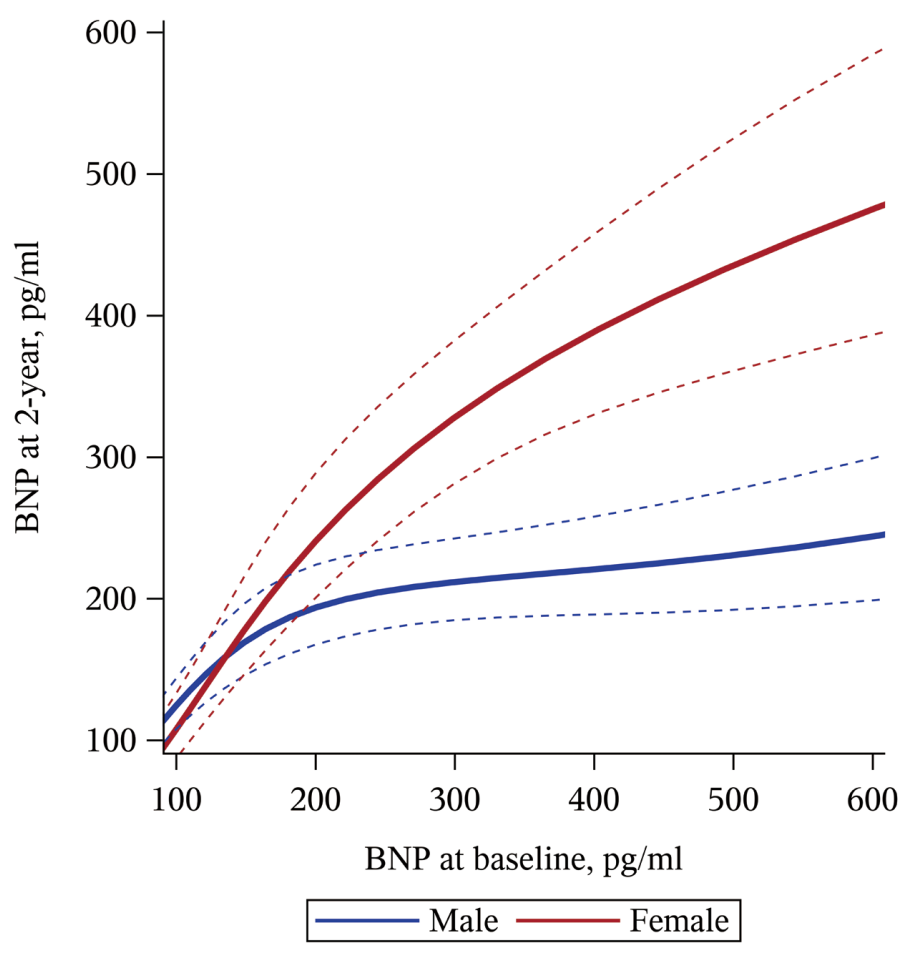

Figure 3. Cubic spline analysis of B-type natriuretic peptide (BNP) at the 2-year follow-up according to sex. Solid lines represents estimated BNP at the 2-year follow-up, with dotted lines indicating the 95\% confidence interval.

\begin{tabular}{|lcccc|}
\hline \multicolumn{1}{|c}{ Table 4. Secondary Outcomes } & Males & Females & $\begin{array}{c}\text { Odds ratio } \\
\text { (95\% Cl) }\end{array}$ & P value \\
De novo HF hospitalization & $25(9.3)$ & $27(15.3)$ & $1.75(0.98-3.13)$ & 0.059 \\
New-onset atrial fibrillation & $10(4.2)$ & $5(2.5)$ & $0.57(0.19-1.71)$ & 0.32 \\
New-onset ventricular arrhythmia & $22(9.4)$ & $14(6.9)$ & $0.71(0.35-1.43)$ & 0.34 \\
New-onset stroke & $5(1.4)$ & $4(1.6)$ & $1.11(0.30-4.18)$ & 0.88 \\
\hline
\end{tabular}

$\mathrm{Cl}$, confidence interval; $\mathrm{HF}$, heart failure.

It is generally known that women have higher BNP concentrations. ${ }^{24}$ Thus, there is a possibility that what is generally said is also true in HCM patients. However, in the present study in HCM patients, we demonstrated that females had higher BNP concentrations at the 2-year follow-up than males after adjusting for baseline BNP. This finding indicates that the sex difference in BNP in HCM patients is not only a reflection of the BNP concentration at baseline.

LV diastolic dysfunction and LV mass are associated with BNP concentrations. Female patients with HCM are reported to have greater diastolic dysfunction than males. ${ }^{12,25}$ Although E and A waves and the E/e' ratio were higher and deceleration time was longer in females than in males (Table 1), these factors could not be analyzed because almost half of them had missing values in the present study. Conversely, LV wall thickness and left atrial diameter, an indicator of diastolic dysfunction, were smaller in females despite their higher BNP concentrations (Table 1), and the BNP concentrations at the 2-year follow-up were higher in females independent of these factors (Table 3). Body surface area (BSA) should be considered in the evaluation of wall thickness and chamber size. However, unfortunately, the database used in this study did not have information about height, body weight, and BSA. In general, BSA is smaller in females than males. ${ }^{26}$ Thus, LV wall thickness and left atrial diameter indexed for BSA may not be that much smaller in females than in males. To elucidate the association between these factors and sex differences in BNP, further investigations are needed.

Females are known to have a higher prevalence of the obstructive phenotype, possibly due to smaller hearts than males, ${ }^{4,6,9}$ which could lead to more severe HF symptoms. ${ }^{4,6}$ In the present study, the obstructive phenotype was more frequent in females (Table 1). However, female sex was independently associated with higher BNP concentrations at the 2-year follow-up, even after adjusting for the obstructive phenotype (Table 2), indicating that the obstructive phenotype does not explain sex differences in BNP concentrations.

The present study demonstrated a predominance of males in the HCM cohort (Table 1), which is consistent with previous studies. ${ }^{4-7}$ Rowin et al reported that the less frequent HCM diagnosis in females was associated with a 
delay in clinical recognition. ${ }^{13}$ In addition, more severe cellular remodeling has been detected in females than males because of a more advanced disease stage at the time of treatment. ${ }^{27}$ Therefore, disease duration is important for the evaluation of BNP concentrations. In fact, the present study demonstrated that disease duration was associated with BNP concentrations at the 2-year follow-up (Table 3). Nevertheless, there were no significant sex differences in the age at registration or that at the time of HCM diagnosis (Table 1), suggesting that the male predominance was not necessarily explained by under-recognition of HCM in females. Furthermore, although age and cardiac function affect higher BNP concentrations in females, multivariate analysis showed that females had higher BNP at the 2-year follow-up than males independent of age and LVEF (Table 2).

Medical treatment should also be considered because it can affect BNP. Beta-blockers are effective in HCM with LV outflow tract obstruction, ${ }^{28}$ and ACEI/ARB lower the risk of new-onset atrial fibrillation ${ }^{29}$ and decrease LV mass. ${ }^{30}$ These drugs could have decreased the BNP concentrations in the present study. However, sex affected BNP concentrations at the 2-year follow-up independent of these medications (Table 2). Intriguingly, cubic spline analysis demonstrated that females with high BNP concentrations at baseline did not tend to have lower BNP concentrations at the 2-year follow-up compared with males. There is a possibility that females with HCM may be refractory to therapy. Although most previous studies analyzed sex differences in BNP cross-sectionally, this study provides a novel finding regarding the association of sex with longitudinal changes in BNP.

A previous study showed that the ratio of the more compliant N2BA/stiffer N2B titin isoforms was higher and interstitial fibrosis was greater in females than males. ${ }^{\mathbf{1 2}}$ The $\mathrm{N} 2 \mathrm{BA} / \mathrm{N} 2 \mathrm{~B}$ ratio has been shown to be associated with myocardial stiffness. ${ }^{31-33}$ The switch to longer titin isoforms may be an attempt to compensate for the diastolic dysfunction. In an animal diabetic model, female rats had higher levels of compliant titin isoforms, and female sex hormones modulated titin isoform expression and collagen deposition. ${ }^{34}$ These differences in microstructure may be related to sex differences in BNP concentrations.

The role of sex hormones in the pathogenesis of $\mathrm{HF}$ is also the subject of debate. ${ }^{35,36}$ The drop in estrogen during the menopausal transition may have affected the results. Age-adjusted mortality is reduced by $2 \%$ with each increasing year of age at menopause, ${ }^{37}$ indicating that later menopause is associated with a decreased cardiovascular risk. Interestingly, estrogenic compounds recapitulated the fibrotic, proapoptotic, and negative hemodynamic effects in male HCM mice. ${ }^{38}$ Sex hormones are potentially involved in sex differences in BNP concentrations among HCM patients.

When the relationship between sex differences in BNP and cardiac dysfunction or prognosis among HCM patients is revealed, it may be possible to identify high-risk patients and preventive strategies for the transition to dilated phase according to sex.

\section{Study Limitations}

Several potential limitations must be acknowledged in the present study. First, we did not have information regarding mortality, cardiovascular events, or rehospitalization due to HF because the Clinical Personal Record did not contain these data. We were only able to evaluate de novo HF hospitalization, new-onset atrial fibrillation and ventricular arrhythmia, and new-onset stroke. We could not determine whether this sex difference is only a reflection of that in the general cohort or not. Further investigations are needed to elucidate the relationship between sex differences in BNP and prognosis in HCM patients.

Second, there is a difference between Europe and Japan in the diagnostic criteria for HCM. According to the 2014 European Society of Cardiology Guidelines on the Diagnosis and Management of Hypertrophic Cardiomyopathy ${ }^{39} \mathrm{HCM}$ is defined by a wall thickness $\geq 15 \mathrm{~mm}$ in $\geq 1$ LV myocardial segments that is not explained solely by loading conditions. Conversely, in the 2012 HCM Japanese guidelines, HCM is defined as an asymmetric or diffuse LV hypertrophy with reduced diastolic function in the absence of any specific cardiac or systemic diseases. In the Clinical Personal Record, certified cardiologists diagnosed HCM according to this definition, guaranteeing the accuracy of diagnosis before registration. In comparison with data in other county, the differences in diagnostic criteria should be considered.

Third, genetic testing results were lacking for most of the patients. The $M Y H 7-\mathrm{R} 403 \mathrm{Q}$ mutation is associated with a shorter life expectancy, ${ }^{40}$ but mutations in $M Y B P C$ have been shown to be associated with a later onset and milder disease characteristics, ${ }^{\mathbf{4 1 - 4 3}}$ which may affect the results of the present study. Fourth, three-quarters of patients in the Clinical Personal Record database were excluded from this study because they did not have their BNP assessed at the 2-year follow-up, which could have led to potential selection bias. The excluded patients were slightly older than those included in the study, but there were no differences in other variables, including BNP at baseline (Supplementary Table 1). In addition, in this cohort, BNP concentrations were higher in females than in males (median [IQR] 182.8 [86.1-363.9] vs. 320.3 [159.0-583.1] pg/mL). These findings indicate that there are no critical differences in background between the 2 groups and support our result of sex differences in BNP.

Finally, the present study is an observational study. Thus, we cannot completely exclude other unmeasured factors that may have affected outcomes, despite validation of sex differences in BNP concentrations by several sensitivity analyses.

Despite the limitations described above, we analyzed clinical characteristics and time-dependent changes in BNP concentrations using a large-scale database of HCM. This study provides important insights for better stratification and therapeutic strategies for HCM.

\section{Conclusions}

Female sex is associated with higher BNP concentrations in HCM than male sex, independent of cardiac systolic function, morphology, medical treatment, and BNP concentrations at baseline.

\section{Acknowledgments}

This study could not have been conducted without the help, cooperation, and support of the cardiologists in the survey institutions. The authors thank these cardiologists for allowing the data to be collected.

\section{Sources of Funding}

This work was supported by grants from the Health Sciences Research 
Grants from the Japanese Ministry of Health, Labour and Welfare (Comprehensive Research on Cardiovascular Diseases; 20FC1051) and grants from the Japan Agency for Medical Research and Development (AMED; No. 19ek0109367 h0002, 20ek0109367 h0003) to H.T.

\section{Disclosures}

H.T. reports personal fees from MSD, Astellas, Pfizer, Bristol-Myers Squibb, Otsuka Pharmaceutical, Daiichi-Sankyo, Mitsubishi Tanabe Pharma, Nippon Boehringer Ingelheim, Takeda Pharmaceutical, Bayer Yakuhin, Novartis Pharma, Kowa Pharmaceutical, Teijin Pharma, Medical Review Co., and the Japanese Journal of Clinical Medicine; non-financial support from Actelion Pharmaceuticals, Mitsubishi Tanabe Pharma, Nippon Boehringer Ingelheim, Daiichi-Sankyo, IQVIA Services Japan, and Omron Healthcare Co.; and grants from Astellas, Novartis Pharma, Daiichi-Sankyo, Takeda Pharmaceutical, Mitsubishi Tanabe Pharma, Teijin Pharma, and MSD outside the submitted work. T.I. is an Associate Editor of Circulation Reports. The other authors declare no conflicts of interest associated with this manuscript.

\section{IRB Information}

The original study protocol was approved by the Institutional Review Board at Kyushu University (No. 29-48).

\section{Data Availability}

The deidentified participant data will not be shared.

\section{References}

1. Maron BJ, McKenna WJ, Danielson GK, Kappenberger LJ, Kuhn HJ, Seidman CE, et al. American College of Cardiology/ European Society of Cardiology clinical expert consensus document on hypertrophic cardiomyopathy: A report of the American College of Cardiology Foundation Task Force on Clinical Expert Consensus Documents and the European Society of Cardiology Committee for Practice Guidelines. Eur Heart J 2003; 24: $1965-$ 1991.

2. Richard P, Charron P, Carrier L, Ledeuil C, Cheav T, Pichereau $\mathrm{C}$, et al. Hypertrophic cardiomyopathy: Distribution of disease genes, spectrum of mutations, and implications for a molecular diagnosis strategy. Circulation 2003; 107: 2227-2232.

3. Marian AJ. Modifier genes for hypertrophic cardiomyopathy. Curr Opin Cardiol 2002; 17: 242-252.

4. Olivotto I, Maron MS, Adabag AS, Casey SA, Vargiu D, Link MS, et al. Gender-related differences in the clinical presentation and outcome of hypertrophic cardiomyopathy. J Am Coll Cardiol 2005; 46: 480-487.

5. O'Mahony C, Jichi F, Ommen SR, Christiaans I, Arbustini E, Garcia-Pavia $P$, et al. International external validation study of the 2014 European Society of Cardiology guidelines on sudden cardiac death prevention in hypertrophic cardiomyopathy (EVIDENCE-HCM). Circulation 2018; 137: 1015-1023.

6. Geske JB, Ong KC, Siontis KC, Hebl VB, Ackerman MJ, Hodge $\mathrm{DO}$, et al. Women with hypertrophic cardiomyopathy have worse survival. Eur Heart J 2017; 38: 3434-3440.

7. Ho CY, Day SM, Ashley EA, Michels M, Pereira AC, Jacoby D, et al. Genotype and lifetime burden of disease in hypertrophic cardiomyopathy: Insights from the Sarcomeric Human Cardiomyopathy Registry (SHaRe). Circulation 2018; 138: 1387-1398.

8. Meghji Z, Nguyen A, Fatima B, Geske JB, Nishimura RA, Ommen SR, et al. Survival differences in women and men after septal myectomy for obstructive hypertrophic cardiomyopathy. JAMA Cardiol 2019; 4: 237-245.

9. Bos JM, Theis JL, Tajik AJ, Gersh BJ, Ommen SR, Ackerman MJ. Relationship between sex, shape, and substrate in hypertrophic cardiomyopathy. Am Heart $J$ 2008; 155: $1128-1134$.

10. Wang Y, Wang J, Zou Y, Bao J, Sun K, Zhu L, et al. Female sex is associated with worse prognosis in patients with hypertrophic cardiomyopathy in China. PLoS One 2014; 9: e102969.

11. van Velzen HG, Schinkel AFL, Baart SJ, Huurman R, van Slegtenhorst MA, Kardys I, et al. Effect of gender and genetic mutations on outcomes in patients with hypertrophic cardiomyopathy. Am J Cardiol 2018; 122: 1947-1954.

12. Nijenkamp L, Bollen IAE, van Velzen HG, Regan JA, van Slegtenhorst M, Niessen HWM, et al. Sex differences at the time of myectomy in hypertrophic cardiomyopathy. Circ Heart Fail 2018; 11: e004133.
13. Rowin EJ, Maron MS, Wells S, Patel PP, Koethe BC, Maron BJ. Impact of sex on clinical course and survival in the contemporary treatment era for hypertrophic cardiomyopathy. J Am Heart Assoc 2019; 8: $\mathrm{e} 012041$.

14. Lu DY, Ventoulis I, Liu H, Kudchadkar SM, Greenland GV, Yalcin H, et al. Sex-specific cardiac phenotype and clinical outcomes in patients with hypertrophic cardiomyopathy. Am Heart $J$ 2020; 219: 58-69.

15. Olsson LG, Swedberg K, Cleland JG, Spark PA, Komajda M, Metra M, et al. Prognostic importance of plasma NT-pro BNP in chronic heart failure in patients treated with a beta-blocker: Results from the Carvedilol Or Metoprolol European Trial (COMET) trial. Eur J Heart Fail 2007; 9: 795-801.

16. Morrow DA, de Lemos JA, Blazing MA, Sabatine MS, Murphy SA, Jarolim P, et al. Prognostic value of serial B-type natriuretic peptide testing during follow-up of patients with unstable coronary artery disease. JAMA 2005; 294: 2866-2871.

17. Carvalho LSF, Bogniotti LAC, de Almeida OLR, Quinaglia e Silva JC, Nadruz W, Coelho OR, et al. Change of BNP between admission and discharge after ST-elevation myocardial infarction (Killip I) improves risk prediction of heart failure, death, and recurrent myocardial infarction compared to single isolated measurement in addition to the GRACE score. Eur Heart $J$ Acute Cardiovasc Care 2019; 8: 643-651.

18. Masson S, Latini R, Anand IS, Barlera S, Angelici L, Vago T, et al. Prognostic value of changes in N-terminal pro-brain natriuretic peptide in Val-HeFT (Valsartan Heart Failure Trial). $J$ Am Coll Cardiol 2008; 52: 997-1003.

19. Minami Y, Haruki S, Kanbayashi K, Maeda R, Itani R, Hagiwara $\mathrm{N}$. B-Type natriuretic peptide and risk of sudden death in patients with hypertrophic cardiomyopathy. Heart Rhythm 2018; 15: $1484-1490$.

20. Pieroni M, Bellocci F, Sanna T, Verardo R, Ierardi C, Maseri A, et al. Increased brain natriuretic peptide secretion is a marker of disease progression in nonobstructive hypertrophic cardiomyopathy. J Card Fail 2007; 13: 380-388.

21. Miyaji Y, Iwanaga Y, Nakamura T, Yasuda M, Kawamura T, Miyazaki S. Interrelationship between the myocardial mass, fibrosis, BNP, and clinical outcomes in hypertrophic cardiomyopathy. Intern Med 2016; 55: 1261-1268.

22. Siriwardena M, Bagai A, Delgado D, Ross HJ, Rozenblyum E, Rakowski H, et al. Prognostic implications of point-of-care and serial B-type natriuretic peptide levels in patients with hypertrophic cardiomyopathy. Am J Cardiol 2018; 122: 1421-1428.

23. Enzan N, Matsushima S, Ide T, Kaku H, Tohyama T, Funakoshi $\mathrm{K}$, et al. Clinical characteristics and contemporary management of patients with cardiomyopathies in Japan: Report from a national registry of Clinical Personal Records. Circ Rep 2021; 3: $142-152$.

24. Clerico A, Del Ry S, Maffei S, Prontera C, Emdin M, Giannessi D. The circulating levels of cardiac natriuretic hormones in healthy adults: Effects of age and sex. Clin Chem Lab Med 2002; 40: $371-377$.

25. Chen YZ, Qiao SB, Hu FH, Yuan JS, Yang WX, Cui JG, et al. Left ventricular remodeling and fibrosis: Sex differences and relationship with diastolic function in hypertrophic cardiomyopathy. Eur J Radiol 2015; 84: 1487-1492.

26. Yoshizumi T, Shirabe K, Nakagawara H, Ikegami T, Harimoto $\mathrm{N}$, Toshima T, et al. Skeletal muscle area correlates with body surface area in healthy adults. Hepatol Res 2014; 44: 313-318.

27. Nijenkamp L, Bollen IAE, Niessen HWM, Dos Remedios CG, Michels M, Poggesi C, et al. Sex-specific cardiac remodeling in early and advanced stages of hypertrophic cardiomyopathy. PLoS One 2020; 15: e0232427.

28. Cabrera-Bueno F, Garcia-Pinilla JM, Gomez-Doblas JJ, MontielTrujillo A, Rodriguez-Bailon I, de Teresa-Galvan E. Beta-blocker therapy for dynamic left ventricular outflow tract obstruction induced by exercise. Int J Cardiol 2007; 117: 222-226.

29. Huang CY, Yang YH, Lin LY, Tsai CT, Hwang JJ, Chen PC, et al. Renin-angiotensin-aldosterone blockade reduces atrial fibrillation in hypertrophic cardiomyopathy. Heart 2018; 104: 12761283.

30. Yamazaki T, Suzuki J, Shimamoto R, Tsuji T, Ohmoto-Sekine Y, Ohtomo K, et al. A new therapeutic strategy for hypertrophic nonobstructive cardiomyopathy in humans. A randomized and prospective study with an angiotensin II receptor blocker. Int Heart J 2007; 48: 715-724

31. Nagueh SF, Shah G, Wu Y, Torre-Amione G, King NM, Lahmers $\mathrm{S}$, et al. Altered titin expression, myocardial stiffness, and left ventricular function in patients with dilated cardiomyopathy. 
Circulation 2004; 110: 155-162.

32. Williams L, Howell N, Pagano D, Andreka P, Vertesaljai M, Pecor T, et al. Titin isoform expression in aortic stenosis. Clin Sci (Lond) 2009; 117: 237-242.

33. Neagoe C, Kulke M, del Monte F, Gwathmey JK, de Tombe PP, Hajjar RJ, et al. Titin isoform switch in ischemic human heart disease. Circulation 2002; 106: 1333-1341.

34. Bupha-Intr T, Oo YW, Wattanapermpool J. Increased myocardial stiffness with maintenance of length-dependent calcium activation by female sex hormones in diabetic rats. Am J Physiol Heart Circ Physiol 2011; 300: H1661 - H1668.

35. Maass AH, Ikeda K, Oberdorf-Maass S, Maier SK, Leinwand LA. Hypertrophy, fibrosis, and sudden cardiac death in response to pathological stimuli in mice with mutations in cardiac troponin T. Circulation 2004; 110: 2102-2109.

36. O'Connell TD, Ishizaka S, Nakamura A, Swigart PM, Rodrigo MC, Simpson GL, et al. The alpha $(1 \mathrm{~A} / \mathrm{C})$ - and alpha(1B)-adrenergic receptors are required for physiological cardiac hypertrophy in the double-knockout mouse. J Clin Invest 2003; 111: 1783 1791.

37. Ossewaarde ME, Bots ML, Verbeek AL, Peeters PH, van der Graaf Y, Grobbee DE, et al. Age at menopause, cause-specific mortality and total life expectancy. Epidemiology 2005; 16: 556562.

38. Haines CD, Harvey PA, Luczak ED, Barthel KK, Konhilas JP, Watson PA, et al. Estrogenic compounds are not always cardioprotective and can be lethal in males with genetic heart disease. Endocrinology 2012; 153: 4470-4479.
39. Authors/Task Force Members; Elliott PM, Anastasakis A, Borger MA, Borggrefe M, Cecchi F, Charron P, et al. 2014 ESC guidelines on diagnosis and management of hypertrophic cardiomyopathy: The Task Force for the Diagnosis and Management of Hypertrophic Cardiomyopathy of the European Society of Cardiology (ESC). Eur Heart J 2014; 35: 2733-2779.

40. Watkins H, Rosenzweig A, Hwang DS, Levi T, McKenna W, Seidman CE, et al. Characteristics and prognostic implications of myosin missense mutations in familial hypertrophic cardiomyopathy. $N$ Engl J Med 1992; 326: $1108-1114$

41. Niimura H, Patton KK, McKenna WJ, Soults J, Maron BJ, Seidman JG, et al. Sarcomere protein gene mutations in hypertrophic cardiomyopathy of the elderly. Circulation 2002; 105: 446-451.

42. Niimura H, Bachinski LL, Sangwatanaroj S, Watkins H, Chudley $\mathrm{AE}, \mathrm{McKenna} \mathrm{W}$, et al. Mutations in the gene for cardiac myosin-binding protein $\mathrm{C}$ and late-onset familial hypertrophic cardiomyopathy. $N$ Engl J Med 1998; 338: 1248-1257.

43. Charron P, Dubourg O, Desnos M, Isnard R, Hagege A, Bonne $\mathrm{G}$, et al. Genotype-phenotype correlations in familial hypertrophic cardiomyopathy. A comparison between mutations in the cardiac protein-C and the beta-myosin heavy chain genes. Eur Heart J 1998; 19: 139-145.

\section{Supplementary Files}

Please find supplementary file(s); http://dx.doi.org/10.1253/circrep.CR-21-0110 